\title{
A 66-year-old woman with spontaneous rib fracture
}

\author{
Susan R. Harris PhD PT
}

Competing interests: None declared.

This article has been peer reviewed.

The clinical scenario is fictitious.

Correspondence to:

Susan Harris, susan.harris @ubc.ca

CMAJ 2015. DOI:10.1503 /cmaj.141435
A 66-year-old woman presents to her family physician with an emergency department radiograph report showing a transverse fracture of the posterior right 11 th rib. She states that the rib pain started a few days ago and, when rolling over in bed from her back to her side the previous night, she heard a crack and felt a sharp pain in her right rib cage, precipitating the visit to the emergency department. The patient has a history of longstanding osteopenia (for which she is undergoing treatment with alendronate) and asynchronous bilateral breast cancer, which last occurred in the right breast 16 years ago. On physical examination, this patient has point tenderness over the posterior-lateral portion of the lower ribs on the right side.

\section{Is this patient likely to have metastatic breast cancer?}

A review of this patient's history for the last diagnosis of breast cancer showed that she had a grade 2 tumour $(2.4 \mathrm{~cm})$ with four axillary lymph nodes positive for metastases (stage IIB). Because local or distant recurrences will develop in up to $70 \%$ of patients with node-positive breast cancer ${ }^{1}$ and bone is the most common site for metastases, ${ }^{2}$ it is reasonable to suspect that the rib pain may be due to metastatic disease. A population-based retrospective cohort study of fracture

Box 1: Risk factors for rib fractures

\begin{tabular}{|lc|}
\hline Risk factor & Approximate risk \\
\hline Metastatic breast cancer & $30 \%^{3}$ \\
\hline Aromatase inhibitor therapy & $\begin{array}{c}1.4 \%-11.0 \% \\
(\text { any fracture })^{7}\end{array}$ \\
\hline Radiotherapy of breast or chest wall & $3.6 \%-4.5 \%^{6}$ \\
\hline Prolonged use of bisphosphonates & $7.4 \%^{5}$ \\
\hline Women aged 83 years or older & $40 \%^{4}$ \\
\hline $\begin{array}{l}\text { Early menopause or ovarian ablation secondary to } \\
\text { adjuvant chemotherapy }\end{array}$ & Unknown \\
\hline $\begin{array}{l}\text { Tissue expansion in breast reconstruction } \\
\text { using implants }\end{array}$ & Unknown \\
\hline
\end{tabular}

risk involving 608 women with a history of breast cancer showed that about $30 \%$ of the reported rib fractures were due to metastatic lesions. ${ }^{3}$

\section{What other possible causes for the rib fracture should be ruled in or out?}

In addition to a history of breast cancer, this patient also has long-standing osteopenia (diagnosed at age $46 \mathrm{yr}$ ). A long-term (median followup time $=13.9 \mathrm{yr}$ ), population-based study involving 699 randomly selected adults reported that almost $40 \%$ of the 67 episodes of rib fracture in older adults were "spontaneous" or nontraumatic. ${ }^{4}$ Long-term use of bisphosphonates, e.g., alendronate in this case, has been associated with lowenergy cortical fractures, including rib fractures. ${ }^{5}$

Other factors that likely contributed to the rib fracture in this patient include previous radiotherapy of the right chest wall and axilla following surgery and chemotherapy ${ }^{6}$ and five years of treatment with an aromatase inhibitor after she completed the other treatments (Box 1). ${ }^{7}$ A systematic review of bone health in women who underwent treatment with aromatase inhibitors for early-stage breast cancer showed that these patients were at a 1.5 times greater risk of fracture than patients undergoing treatment with tamoxifen or placebo. ${ }^{7}$

Case reports have suggested that the use of tissue expansion for the placement of breast implants in irradiated tissue may be a risk factor for rib fractures; this patient underwent this procedure following mastectomy. ${ }^{8,9}$

\section{What additional tests should be ordered?}

Because of the point tenderness on examination, her family physician ordered a bone scan and blood tests (complete and differential blood cell counts and assays of cancer antigens 125 and 15-3, and carcinoembryonic antigen) after consultation with this patient's medical oncologist. The investigations are recommended by the National Comprehensive Cancer Network in their 2014 breast cancer clinical practice guidelines. ${ }^{10}$

A computed tomography (CT) scan of the chest (without contrast), which is recommended by the European Society for Medical Oncology 
clinical practice guidelines for locally recurrent or metastatic breast cancer, ${ }^{1}$ was ordered next to detect if any osteolytic lesions suggestive of metastatic disease were present. ${ }^{11}$

\section{Case revisited}

The results of the bone scan showed increased activity within the posterior 11 th rib on the right side as well as foci of increased activity within the proximal 5th and 6th ribs on the right side, the latter thought to be associated with previous trauma. The radiologist could not exclude bone metastases at this point. However, all results from the blood tests were within normal limits. Because no osseous abnormalities other than the incident fracture were noted on the CT scan, the radiologist concluded that the rib fracture was due to causes other than metastasis.

Although the initial suspicion was that this patient's spontaneous rib fracture might be due to metastatic breast cancer, results of the bone and CT scans combined with normal tumour markers ruled that out. Her history of osteopenia and long-term alendronate use, as well as the likelihood of radiation damage to the ribs and additional bone loss owing to alendronate use, could have contributed to the pathologic fracture.

Six weeks after the fracture occurred, most of this patient's symptoms had resolved (other than some tenderness at the fracture site when lying on the right side), and the rib fracture had healed. She returned to her usual activities of playing tennis and jogging without further incident. Because the patient had been taking alendronate for 12 years, her family physician recommended that she take a drug holiday for one to two years and then have a repeat dual energy $\mathrm{x}$-ray absorptiometry scan.

\section{References}

1. Cardoso F, Harbeck N, Fallowfield L, et al.; ESMO Guidelines Working Group. Locally recurrent or metastatic breast cancer: ESMO Clinical Practice Guidelines for diagnosis, treatment and follow-up. Ann Oncol 2012;23(supplement 7):vii11-9.
2. Chen HH, Su WC, Guo HR, et al. Clinical significance and outcome of one or two rib lesions on bone scans in breast cancer patients without known metastases. Nucl Med Commun 2003;24:1167-74.

3. Melton LJ 3rd, Hartmann LC, Achenbach SJ, et al. Fracture risk in women with breast cancer: a population-based study. $J$ Bone Miner Res 2012;27:1196-205.

4. Wuermser LA, Achenbach SJ, Amin S, et al. What accounts for rib fractures in older adults? J Osteoporos 2011;2011: 457591.

5. Armamento-Villareal R, Napoli N, Diemer K, et al. Bone turnover in bone biopsies of patients with low-energy cortical fractures receiving bisphosphonates: a case series. Calcif Tissue Int 2009;85:37-44

6. Smith GL, Xu Y, Buchholz TA, et al. Association between treatment with brachytherapy vs whole-breast irradiation and subsequent mastectomy, complications, and survival among older women with breast cancer. JAMA 2012;307:1827-37.

7. Becker T, Lipscombe L, Narod S, et al. Systematic review of bone health in older women treated with aromatase inhibitors for breast cancer. J Am Geriatr Soc 2012;60:1761-7.

8. Tseng J, Huang AH, Wong MS, et al. Rib fractures: a complication of radiation therapy and tissue expansion for breast reconstruction. Plast Reconstr Surg 2010;125:65e-6e.

9. Tirone L, La Rusca I, Cicarelli F. Rib fracture as a complication of tissue expansion in breast reconstruction. Plast Reconstr Surg 2010;126:2290-1.

10. National Comprehensive Cancer Network clinical practice guidelines in oncology. Breast cancer. Fort Washington (PA): National Comprehensive Cancer Network; 2014. Available: www.ncen .org/professionals/physician_gls/f_guidelines.asp\#breast (accessed 2015 Jan. 26).

11. Lipton A, Uzzo R, Amato RJ, et al. The science and practice of bone health in oncology: managing bone loss and metastasis in patients with solid tumors. J Natl Compr Canc Netw 2009; 7(Suppl 7):S1-29.

Physician resources can be found in Appendix 1 available at www.cmaj.ca/lookup/suppl/doi:10.1503/cmaj.141435/-/DC1

Affiliation: Department of Physical Therapy, Faculty of Medicine, The University of British Columbia, Vancouver, BC

Decisions is a series that focuses on practical evidence-based approaches to common presentations in primary care. The articles address key decisions that a clinician may encounter during initial assessment. The information presented can usually be covered in a typical primary care appointment. Articles should be no longer than 650 words, may include one box, figure or table and should begin with a very brief description (75 words or less) of the clinical situation. The decisions addressed should be presented in the form of questions. A box providing helpful resources for the patient or physician is encouraged. 